\title{
Geographies of informal care in Ireland, 2002-2006
}

\author{
Ronan Foley* \\ Department of Geography, National University of Ireland, Maynooth, Ireland
}

\begin{abstract}
Given the increasing role that informal caregivers play in the Irish health, social and economic systems, this short empirical paper outlines and maps the spatial distribution of caregivers from the 2002 and 2006 Censuses to provide some preliminary insights into patterns of caregiving in Ireland. The primary tasks involved mapping the distribution of carers at small area-level in both 2002 and 2006 and noting specific changes in patterns from the 2006 data. Patterns of informal caring are discussed in relation to: (a) clusters and concentrations (as measured by location quotients), (b) specific distributions related to intensities of caring, (c) key changes noted between 2002 and 2006 and (d) some preliminary explorations of explanatory data. Associations were identified between high-intensity caring and age, social class, deprivation and working in the home. Finally, potential applied policy uses for data for informal caring are identified including needs assessment and as an evidence base for modelling spatial service equity.
\end{abstract}

Keywords: carers; informal care; spatial distributions; equity; health geography

\section{Introduction and context}

In Ireland, carers are estimated to save the state approximately €2bn per annum in health care costs annually (Guidera 2001). A carer can be defined as:

An individual who provides assistance and support, on an unpaid basis, to family members, relatives or friends who need such care because of disability, old age or long-term illness (The Equality Authority 2005, iii).

The process of informal, as opposed to institutionally based, caring has always taken place in the home, whereby a variety of individuals and groups have looked after elderly or disabled family members or friends, with little or no contact with formal agencies (Glendinning and McLoughlin 1993; Stalker 1996). There has been an increased recognition and understanding of the role that informal carers play within national health and social care systems (Milligan 2001). Most caregivers need support in their role as carers, especially if they are engaged in caring for substantial parts of the day. This support can take a number of forms, ranging from moral or psychological support and information on entitlements to direct service provision in the form of respite care (Stalker 1996; Ashworth and Baker 2000; Milligan 2000). The support a carer receives is often confused or conflated with the needs of the cared-for person (indirect services), whether that be a disabled child, adult or older person. It is important to be clear on that distinction (Parker and Lawton 1994). Unlike the UK, there is no statutory basis for needs assessment and carer's support in Ireland (The Equality Authority 2005). With the increased recognition of informal carers also occurring in other European and North American countries, there has

*Email: ronan.foley@nuim.ie 
been, not surprisingly, an increase in carer research in recent decades (Rowlands 1998; O’Neill and Evans 1999; Lane et al. 2000; Power 2005). The result has been a political response in the form of legislation and promises of improved or enhanced service provision (Timonen 2002; Power 2005; The Equality Authority 2005).

The geographical literature on caregiving has been much more recent than that of wider discussions on related subjects such as disability. Kearns (1993) first observed that there was no adequate analysis of caregiving that adopted a place-centred theoretical perspective. Much of the subsequent work focused upon home care given to the elderly (Milligan 2000; Wiles 2003), the chronically ill (Thomas and Morris 2002) or children with learning disabilities (Foley 2002). This research has been fuelled in part by the cultural turn in geography, which has focused less on biomedical and more on social models of medicine and health (Curtis 2004). Linked to these social models, there has been a developing interest in geographies of social care (Milligan 1998, 2001; Foley 2002; Williams 2002). The two main strands within this work have been the examination of home care service provision (Williams 1996; Fyfe and Milligan 2003; Foley 2002) and the changing nature of the home space (Milligan 2000; Williams 2002; Wiles 2003). A more recent theoretical direction is an interest in what might be termed 'geographies of volunteerism' and a recognition that caring, along with other informal processes, is something which exists outside statutory and private structures and that there are varied and complex geographies associated with this 'third way' (Hanlon 2001; Power 2005; Skinner and Rosenberg 2005; Milligan and Conradson 2006). A further spatial aspect relevant to the research is the relative importance of place effects (context) versus the role of individuals as agents (composition). The extent to which primacy can be ascribed to place or the individuals within that place continues to inform and shape debates in the geographies of care (Shaw et al. 2002).

While all the above research has at its core concerns with service provision and support for informal carers, evidence of the actual extent of informal caring has arguably been neglected. Empirical approaches which map the numbers and extents of specific variables have, to an extent, gone out of fashion. However, newly available data for carers in both Ireland and beyond is something which needs to be documented and explored more fully. Recent research within the wider health inequalities field in the past decade has explored relationships between social and economic variables, both cartographically and statistically (Boyle et al. 2001; Young et al. 2005). In the literature for health geography and carers, a common theme is emerging around the need for detailed spatial data to inform service planning and delivery. This also sits well within the wider theoretical interest in geographies of social care and volunteerism (Milligan and Conradson 2006). Linked to this, and implicit in any study that looks at the spatial distribution of a sub-population, is the consideration of equity. In an ideal service setting the supply of services will match the location of potential users and effectively match supply with demand. In this case, mapping the location of carers, and especially the location of high-intensity caring, acts as a useful proxy for need. This, in turn, can potentially be used to look at the distribution of supply of services to help identify the existence or otherwise of spatial equity. Typically, the kinds of services which carers would access would include respite and short-term care services for the carers, day centres, residential centres, vocational training and sheltered workshops for the care recipients. While this paper does not aim to develop the supply side, by looking at the distribution of caring as an activity the potential to begin to predict inequalities in relation to intensities of care is advanced. For the first time ever, questions on levels of care giving were included in both the 2001 Census in the UK (including Northern Ireland) and in the 2002 Irish Census, with the latter repeated in the 2006 Irish Census. As a result, it has 
become possible to empirically map these data. The aim of the paper is to provide an initial analysis of spatial patterns of informal care in Ireland. Within this aim there are four objectives; namely, to identify spatial concentrations, to look at specific distributions related to intensities of caring, to note key changes between 2002 and 2006 and to provide a starting-point for discussions on causality and explanation.

\section{Data and method}

From a health and social care perspective, it is important for planners to use all available evidence to inform policy, with a particular emphasis on the potential of new data to inform needs assessment. This is where geographers have a particular role to play (Milligan 2001; Foley 2002; Gatrell 2002). The geographical focus of this current work is at the national, regional, county and electoral division (ED) levels, using data in the Censuses of 2002 and 2006. By having detailed data for the first time, it was possible to identify which parts of the country had the highest relative levels of caring activity. Actual individual counts also provide core information for health and social care planning purposes.

From evidence in the literature, women have traditionally provided more care than men, certain age-groups have provided the most care and certain types of geographical areas have been associated with higher levels of caring (Glendinning and McLaughlin 1993; Stalker 1994; Carers UK 2005). Given these findings from other locations, it was considered valuable to tease out some preliminary explanations for patterns of caring at a detailed geographical scale within Ireland. As it is only in the past decade or so that the role of geography and socio-spatial information generally has begun to filter down into social care planning, the recent availability of these counts for Ireland is also timely. By looking at these data sets in detail for the first time, it may be possible to assess their potential in explaining patterns and relationships and their potential strategic value to decision-making and service delivery. They may also provide a reference point for previous survey-based estimates of carers in Ireland (O'Neill and Evans 2000; O'Shea 2000).

Until 2001, data on carers in both the UK and Ireland were confined almost entirely to surveys, which indicated who carers were and, to an extent, what needs they had (Parker 1992; Stalker 1994; Rowlands 1998; Timonen 2002). There was more limited information on their geographical distribution and how need varied across space (Parker 1992; Timonen 2002). In order to determine exactly where carers lived and the nature of their needs, a decision was made by the Irish Central Statistics Office (CSO) to ask a question on caring in the 2002 Census (CSO 2004). The CSO stated that:

The results of question 23 will facilitate an assessment to be made of the extent to which unpaid personal help is provided by carers in our society, along with the demographic and socio-economic characteristics of the carers themselves. This question is being asked for the first time in Census 2002 (CSO 2005).

This initial count in Ireland followed an equivalent initial count in the UK Census of 2001 (Office of National Statistics 2003). The UK counts will provide a cognate and relevant comparison for some of the ideas to be developed in this paper (Dixie and Dorling 2002). Once data were collected in the Census, it was possible to gain new information on the location of carers, the extent of their caring responsibilities and to establish whether there were any relationships between geographies of caring and other geographical variables.

In the 2002 Irish Census, the relevant question sought information on individual carers and the hours a week spent on caring (CSO 2004). Results were reported at national, regional and local scales, enabling data to be cross-tabulated with information on age, 
gender, family structure, housing tenure and social class to provide a broad general profile of carers in Ireland at this time (CSO 2004). According to the definition used by the CSO, a carer was:

An individual providing regular unpaid personal help for a friend or family member with a long-term illness, health problem or disability (including problems due to old age: Personal help includes help with basic task such as feeding or dressing) (CSO 2004).

The question on the amount of time spent in caring was broken down into four broad classes; namely, one to 14 hours a week (low-intensity, or LI), 15-28 hours a week (medium-intensity, or MI), 29-42 hours a week (high-intensity, or HI) and 43+ hours a week (maximum-intensity, or XI). Distinguishing between levels of care was important as it was the final maximum-intensity group who were most likely to need various forms of support services (Glendinning 2002; The Equality Authority 2005). While it is important to acknowledge that the intensity classifications noted above are very broad and would, in turn, be affected by the specific type of care needed and the demands of that care, a level of knowledge about carer's time burdens was still an essential piece of background knowledge (CSO 2004; The Equality Authority 2005). The same question formats and classifications were used subsequently in the 2006 Census (CSO 2007). For much of the analysis in this paper, the focus will be on the generic (All) and maximum-intensity (XI) categories given the bi-modal nature of the data. The proportions of MI and HI caring are much smaller in comparison to the other two.

As stated previously, the major objective of the paper is to look at the relative spread of informal caring in Ireland, given a wider interest in health inequalities and the potential of the data to aid planning to reduce inequality. The wider literature in medical/health geography has always had an interest in equity as expressed through relative levels of particular patterns of demand. Joseph and Philips (1984) offer a useful summary of core ideas around measuring need, and used 'location quotients' to provide a simple but effective comparative measure that can be used to examine the relative levels of activities. Their formula can be applied to caring in Ireland to provide a national visualisation of the relative level of care-giving activities. The basic formula is expressed as:

$$
\begin{aligned}
& \mathrm{LQ}[t i]=\frac{\mathrm{SP}[t i] / \mathrm{P}[t i]}{\sum i \mathrm{SP}[t i] / \sum \mathrm{iP}[t i]}
\end{aligned}
$$

where: $\mathrm{LQ}[t i]=$ location quotient for region $i$ at time $t, \mathrm{SP}[t i]=$ number of carers in region $i$ at time $t, \mathrm{P}[t i]=$ total population of region $i$ at time $t$.

Essentially, location quotients express the extent to which any identified area varies from the national average. Thus a location quotient score of 2.0 identifies an area with twice the expected number of carers than the national average, whereas a score of 0.5 refers to an area with half the expected number of carers given the national average. Clearly, location quotients are a relatively simple measure, yet for the visualisation of distributions and levels of caring, especially at a small area level, they are an effective tool in establishing national patterns.

\section{Results}

\section{National level}

The full listings of national and county level results are provided in volume 10 of both Census 2002 and Census 2006 (CSO 2004, 2007). It is not the intention to list these in full 
but rather to summarise them before moving on to consider spatial distributions and relationships. The actual recorded count of carers in the 2002 Census was 148,754 , or $4.8 \%$ of the total population over 15 nationally. This compares to $9.9 \%$ nationally in England and Wales in 2001 (Office of National Statistics 2003). The higher rates in the UK are associated, arguably, with greater numbers of post-industrial regions and a more formalised statutory social care system (Boyle et al. 2001). Of the total number of carers in Ireland, 84,862 (57.0\% of all carers) were caring for less than 14 hours a week, 23,366 $(15.7 \%)$ were medium and high intensity while there were 40,526 (27.2\%) maximumintensity carers, caring for 43 hours or more a week. These compare with broadly similar rates in the UK of $68.6 \%$ (low), $10.9 \%$ (medium) and $20.5 \%$ (high), respectively. The variations are related primarily to the fact that the categories in the UK are defined somewhat differently; in particular, the highest UK category (50 hours a week or more) is likely to generate a smaller proportion. The figures were also broadly in line with an earlier CSO pilot (which estimated that there were about 130,000 carers) and estimates identified by O'Shea of around 80,000 carers looking after older people in the country (O'Shea 2000). By 2006, the number of carers had increased to 160,917 . This translates into a rate of $4.8 \%$, which is identical to the wider population increase rate in the same period. In terms of levels of caregiving, the figures for 2006 were $58.0 \%$ (low intensity), 16.6\% (medium/high intensity) and $25.4 \%$ (maximum intensity), respectively. Although the overall breakdowns are similar to 2002, the relative rates declined slightly for the maximum-intensity group, and this will be discussed more fully below.

From the 2002 Census, 91,274 $(61.3 \%)$ of principal carers were women, with a significant proportion of all carers (over 50\%) in the middle age groups of the 40s and 50s. Of the maximum-intensity carers, $66.7 \%$ were female; this group also made up $60.1 \%$ of all carers aged 65 and over (CSO 2004). The proportion of female carers had increased slightly to $62.3 \%$ by 2006 , with a similar proportion of maximum-intensity carers $(65.7 \%)$. Of the recorded carers in 2002, 77,385 (52.0\%) were working and of that sub-group, $21.2 \%$ were engaged in medium-intensity caring and above. The number of working carers was 90,554 in 2006, which at 56.3\% marked a relatively large increase from only four years before. This may be a factor related to wider relative increases in the workforce, but may also suggest greater pressures on carers to work with a concomitant impact on caring activities. The comparative figure for maximum-intensity carers was $21.6 \%$, which was a very small increase from the 2002 figure. At the broad national level for both time periods, the proportions were higher in rural than in urban areas (as measured in the Census by Aggregated Town and Rural Areas). In 2006, the average rates were 4.3\% for urban areas, but $5.4 \%$ for rural areas. This differed from the UK figures, where higher concentrations were found in urban areas. This was explained in part by higher clusters of urbanisation, together with a more concentrated pattern of elderly residents in seaside counties in the South and East of the UK, a pattern less visible in Ireland (Young et al. 2005). Both sets of data confirmed evidence from the carer literature on the relationship between age, gender and caring burdens. This situation is likely to become even more acute given the general demographic trend of people living to a greater age. This has obvious implications for carers and the planning and provision of support services into the future.

\section{County I LA level}

Table 1 lists the overall numbers and location quotients for all carers in 2002 and 2006 at county level. The results for 2002 identified that rural counties in the west such as Roscommon (1.22), Mayo (1.15) and Galway (1.14) had the highest location quotients. 
Table 1. Location quotients for levels of All (ALL) and maximum-intensity (XI) caring, county level, 2002 and 2006.

\begin{tabular}{|c|c|c|c|c|c|c|c|c|c|c|c|c|c|}
\hline Code & $\begin{array}{l}\text { County } \\
\text { Name }\end{array}$ & $\begin{array}{c}\text { Population } \\
\text { over } 15 \text {, } \\
2002\end{array}$ & $\begin{array}{l}\text { Number } \\
\text { of } \\
\text { Carers, } \\
2002\end{array}$ & $\begin{array}{c}\text { Maximum } \\
\text { Intensity } \\
\text { Carers, } \\
2002\end{array}$ & $\begin{array}{l}\text { Population } \\
\text { over } 15 \text {, } \\
2006\end{array}$ & $\begin{array}{l}\text { Number } \\
\text { of } \\
\text { Carers, } \\
2006\end{array}$ & $\begin{array}{c}\text { Maximum } \\
\text { Intensity } \\
\text { Carers, } \\
2006\end{array}$ & $\begin{array}{c}\text { Location } \\
\text { Quotient } \\
2002 \\
\text { ALL } \\
\text { Carers }\end{array}$ & $\begin{array}{c}\text { Location } \\
\text { Quotient } \\
2002 \text { XI } \\
\text { Carers }\end{array}$ & $\begin{array}{c}\text { Location } \\
\text { Quotient } \\
2006 \\
\text { ALL } \\
\text { Carers }\end{array}$ & $\begin{array}{c}\text { Location } \\
\text { Quotient } \\
2006 \text { XI } \\
\text { Carers }\end{array}$ & $\begin{array}{l}\text { Change } \\
\text { in LQ } \\
\text { All 02-06 }\end{array}$ & $\begin{array}{c}\text { Change } \\
\text { in LQ } \\
\text { XI } \\
02-06\end{array}$ \\
\hline 9 & Carlow & 35,951 & 1,600 & 491 & 39,779 & 1,677 & 457 & 0.92 & 1.04 & 0.88 & 0.95 & -0.04 & -0.09 \\
\hline 34 & Cavan & 43,655 & 2,220 & 682 & 49,751 & 2,553 & 708 & 1.06 & 1.19 & 1.08 & 1.17 & 0.02 & -0.02 \\
\hline 27 & Clare & 80,403 & 4,110 & 1,068 & 86,977 & 4,507 & 1,067 & 1.06 & 1.01 & 1.09 & 1.01 & 0.03 & 0.00 \\
\hline 29 & Cork City & 101,927 & 4,954 & 1,370 & 101,254 & 4,855 & 1,268 & 1.01 & 1.02 & 1.01 & 1.03 & 0.00 & 0.01 \\
\hline 33 & Cork County & 252,070 & 12,927 & 3,222 & 283,014 & 14,783 & 3,583 & 1.07 & 0.97 & 1.10 & 1.05 & 0.03 & 0.07 \\
\hline 1 & Donegal & 105,320 & 5,361 & 1,768 & 113,838 & 5,698 & 1,717 & 1.06 & 1.28 & 1.05 & 1.25 & -0.01 & -0.03 \\
\hline 7 & Dublin City & 415,609 & 18,107 & 4,987 & 430,357 & 18,356 & 4,724 & 0.90 & 0.91 & 0.89 & 0.91 & -0.01 & -0.01 \\
\hline 22 & $\begin{array}{l}\text { Dun } \\
\text { Laoghaire- } \\
\text { Rathdown }\end{array}$ & 155,035 & 7,636 & 1,541 & 158,794 & 7,544 & 1,475 & 1.02 & 0.76 & 1.00 & 0.77 & -0.03 & 0.01 \\
\hline 13 & Fingal & 151,821 & 6,940 & 1,514 & 187,018 & 7,997 & 1,701 & 0.95 & 0.76 & 0.90 & 0.75 & -0.05 & -0.01 \\
\hline 8 & Galway City & 55,078 & 2,273 & 526 & 61,264 & 2,409 & 541 & 0.86 & 0.73 & 0.82 & 0.73 & -0.03 & 0.00 \\
\hline 19 & $\begin{array}{l}\text { Galway } \\
\text { County }\end{array}$ & 110,521 & 6,089 & 1,816 & 124,360 & 6,843 & 1,816 & 1.14 & 1.25 & 1.15 & 1.21 & 0.01 & -0.05 \\
\hline 32 & Kerry & 105,813 & 5,597 & 1,653 & 112,587 & 5,892 & 1,599 & 1.10 & 1.19 & 1.10 & 1.17 & 0.00 & -0.02 \\
\hline 28 & Kildare & 125,035 & 5,308 & 1,421 & 143,326 & 5,961 & 1,588 & 0.88 & 0.87 & 0.87 & 0.91 & -0.01 & 0.05 \\
\hline 30 & Kilkenny & 62,260 & 3,111 & 921 & 68,705 & 3,434 & 886 & 1.04 & 1.13 & 1.05 & 1.06 & 0.01 & -0.06 \\
\hline 21 & Laoighis & 45,118 & 2,260 & 680 & 51,895 & 2,472 & 703 & 1.04 & 1.15 & 1.00 & 1.12 & -0.04 & -0.03 \\
\hline 12 & Leitrim & 20,377 & 1,074 & 293 & 23,052 & 1,205 & 304 & 1.09 & 1.10 & 1.10 & 1.09 & 0.00 & -0.01 \\
\hline 23 & $\begin{array}{l}\text { Limerick } \\
\text { City }\end{array}$ & 43,548 & 2,167 & 684 & 43,168 & 2,074 & 653 & 1.03 & 1.20 & 1.01 & 1.25 & -0.03 & 0.05 \\
\hline 31 & $\begin{array}{l}\text { Limerick } \\
\text { County }\end{array}$ & 95,978 & 4,759 & 1,237 & 104,944 & 5,114 & 1,220 & 1.03 & 0.98 & 1.02 & 0.96 & -0.01 & -0.02 \\
\hline 16 & Longford & 24,093 & 1,281 & 423 & 26,928 & 1,381 & 404 & 1.10 & 1.34 & 1.08 & 1.24 & -0.03 & -0.10 \\
\hline 11 & Louth & 78,746 & 3,745 & 1,063 & 86,699 & 4,226 & 1,100 & 0.99 & 1.03 & 1.02 & 1.05 & 0.03 & 0.02 \\
\hline 20 & Mayo & 92,165 & 5,091 & 1,565 & 98,430 & 5,440 & 1,503 & 1.15 & 1.29 & 1.16 & 1.26 & 0.01 & -0.03 \\
\hline 15 & Meath & 102,339 & 4,792 & 1,236 & 124,681 & 5,721 & 1,354 & 0.97 & 0.92 & 0.96 & 0.90 & -0.01 & -0.02 \\
\hline
\end{tabular}




\begin{tabular}{|c|c|c|c|c|c|c|c|c|c|c|c|c|c|}
\hline Code & $\begin{array}{l}\text { County } \\
\text { Name }\end{array}$ & $\begin{array}{c}\text { Population } \\
\text { over } 15 \text {, } \\
2002\end{array}$ & $\begin{array}{c}\text { Number } \\
\text { of } \\
\text { Carers, } \\
2002\end{array}$ & $\begin{array}{c}\text { Maximum } \\
\text { Intensity } \\
\text { Carers, } \\
2002\end{array}$ & $\begin{array}{c}\text { Population } \\
\text { over } 15 \text {, } \\
2006\end{array}$ & $\begin{array}{c}\text { Number } \\
\text { of } \\
\text { Carers, } \\
2006\end{array}$ & $\begin{array}{c}\text { Maximum } \\
\text { Intensity } \\
\text { Carers, } \\
2006\end{array}$ & $\begin{array}{c}\text { Location } \\
\text { Quotient } \\
2002 \\
\text { ALL } \\
\text { Carers }\end{array}$ & $\begin{array}{c}\text { Location } \\
\text { Quotient } \\
2002 \text { XI } \\
\text { Carers }\end{array}$ & $\begin{array}{c}\text { Location } \\
\text { Quotient } \\
2006 \\
\text { ALL } \\
\text { Carers }\end{array}$ & $\begin{array}{c}\text { Location } \\
\text { Quotient } \\
2006 \text { XI } \\
\text { Carers }\end{array}$ & $\begin{array}{c}\text { Change } \\
\text { in LQ } \\
\text { All 02-06 }\end{array}$ & $\begin{array}{c}\text { Change } \\
\text { in LQ } \\
\text { XI } \\
02-06\end{array}$ \\
\hline 25 & Monaghan & 40,819 & 2,104 & 580 & 44,128 & 2,283 & 522 & 1.07 & 1.08 & 1.09 & 0.98 & 0.01 & -0.11 \\
\hline 17 & Offaly & 48,864 & 2,346 & 699 & 54,911 & 2,691 & 733 & 1.00 & 1.09 & 1.03 & 1.10 & 0.03 & 0.01 \\
\hline 10 & Roscommon & 42,357 & 2,482 & 675 & 46,791 & 2,567 & 703 & 1.22 & 1.21 & 1.15 & 1.24 & -0.07 & 0.03 \\
\hline 2 & Sligo & 46,111 & 2,332 & 642 & 48,972 & 2,484 & 637 & 1.05 & 1.06 & 1.06 & 1.07 & 0.01 & 0.01 \\
\hline 4 & South Dublin & 185,164 & 8,037 & 2,054 & 193,355 & 8,346 & 2,047 & 0.90 & 0.85 & 0.91 & 0.87 & 0.00 & 0.03 \\
\hline 14 & $\begin{array}{l}\text { Tipperary, } \\
\text { N.R. }\end{array}$ & 47,694 & 2,505 & 732 & 51,921 & 2,705 & 704 & 1.09 & 1.17 & 1.09 & 1.12 & 0.00 & -0.05 \\
\hline 3 & $\begin{array}{l}\text { Tipperary, } \\
\text { S.R. }\end{array}$ & 61,730 & 3,013 & 909 & 65,693 & 3,263 & 912 & 1.01 & 1.12 & 1.04 & 1.15 & 0.03 & 0.02 \\
\hline 26 & $\begin{array}{l}\text { Waterford } \\
\text { City }\end{array}$ & 35,577 & 1,465 & 383 & 36,970 & 1,640 & 406 & 0.86 & 0.82 & 0.93 & 0.91 & 0.08 & 0.09 \\
\hline 5 & $\begin{array}{l}\text { Waterford } \\
\text { County }\end{array}$ & 44,252 & 2,064 & 556 & 48,574 & 2,491 & 557 & 0.97 & 0.96 & 1.08 & 0.95 & 0.11 & -0.01 \\
\hline 18 & Westmeath & 55,414 & 2,663 & 756 & 61,695 & 2,862 & 731 & 1.00 & 1.04 & 0.97 & 0.98 & -0.03 & -0.06 \\
\hline 6 & Wexford & 90,081 & 4,141 & 1,266 & 102,511 & 4,825 & 1,430 & 0.95 & 1.07 & 0.99 & 1.15 & 0.03 & 0.08 \\
\hline \multirow[t]{3}{*}{24} & Wicklow & 88,850 & 4,200 & 1,113 & 99,057 & 4,618 & 1,130 & 0.98 & 0.96 & 0.98 & 0.94 & 0.00 & -0.01 \\
\hline & $\begin{array}{l}\text { Sums/ } \\
\text { Averages }\end{array}$ & $3,089,775$ & 148,754 & 40,526 & $3,375,399$ & 160,917 & 40,883 & 1.02 & 1.05 & 1.02 & 1.04 & 0.00 & -0.01 \\
\hline & $\begin{array}{l}\text { Standard } \\
\text { Deviations }\end{array}$ & $75,804.01$ & $3,427.28$ & 898.02 & $80,484.66$ & $3,608.63$ & 895.24 & 0.08 & 0.16 & 0.09 & 0.15 & 0.03 & 0.05 \\
\hline
\end{tabular}

Source: CSO, 2007 
The lowest proportions were recorded in urban centres such as Galway (0.86), Kildare (0.88) and some of the Dublin authorities. This broad rural-urban split was relatively pronounced and was replicated in the 2006 figures. Again, Mayo and Roscommon were among the highest, with LQ scores of 1.16 and 1.15, respectively, while lower scores were recorded again in the Greater Dublin authorities, with the lowest value again being recorded in Galway City (0.82). Overall, there was no change in the location quotients apart from a very small increase in the standard deviation.

When location quotients for maximum-intensity (XI) caring for 2002 were tabulated (also included in Table 1), the spatial patterning was similar to the wider group, with the same rural counties emerging with the highest LQs. Rural counties in the West and Northwest such as Mayo, Donegal and Galway all had scores above 1.20, with Longford recording the highest value at 1.34 . The lowest maximum-intensity location quotients were also to be found again in Galway City and in urban authorities such as Fingal and Dun Laoghaire-Rathdown. In these counties, arguably urbanisation, relative wealth and a younger population may well have accounted for these differences reflecting evidence from the UK (Duncan and Smith 2002; Young et al. 2005). The more ready availability of nursing homes and other forms of alternative and private support might be an additional factor. When the location quotient scores for maximum-intensity carers in 2006 were examined, similar spatial patterns emerged with Roscommon, Mayo, Donegal and Longford all in the top five of the rankings while Galway City, Fingal and Dun Laoghaire-Rathdown again recorded the lowest location quotients, and by extension, the lowest relative levels of caring burdens. There was a very small reduction in both the mean and standard deviation of the county level data for XI caring.

The final two columns in Table 1 record changes in the location quotients between 2002 and 2006 for both All and XI carer categories. There is little variation apparent in the overall LQ score for carers, and indeed the average county LQ score remains the same at 1.02, just over the national average. In addition, the average LQ score for the XI carers and reductions are also broadly similar for 2002 and 2006. The average LQ score was 1.05 in 2002 and was marginally reduced to 1.04 in 2006 with an average LQ score variation of -0.01 per county. Spatially the greatest reduction in the overall carer LQ score was found in Roscommon, followed by Fingal and Laois. For XI caring, the greatest reductions in LQ score were found in Monaghan, Longford and Carlow. These were all rural counties, with arguably similar standards of living and all at the fringes of the commuter belt around Dublin, a region associated typically with lower levels of caring. This suggested a trickle-down effect related to urban-driven commuting catchments, which typically had younger populations who, in turn, were less likely to be involved in caring. At the other end of the scale, both Waterford City and County experienced the largest increases in overall caring between 2002 and 2006, although for XI caring this was associated more with the city than the county. The other county showing an increase in XI caring was Wexford, which is suggestive of a broad regional pattern of increased care burdens in the South East. While the time scale involved is very short, what the patterns suggest is a relative stability in caring over time and space. The stability is important, in that it suggests that one can plan for the future with reasonable certainty, and it also provides a measure against which changes can be mapped, especially when investigating spatial equity over a longer time period.

\section{ED level}

While county-level data provide valuable evidence about the broad geographical distributions of carers, mapping the data as location quotients at ED level enables a 
more detailed exploration of localised patterns in both 2002 and 2006 (Figures 1 and 2, respectively). With 3424 different counts the range of values was, as would be expected, greater than at the county level; the range was from 0.00 to 3.48 for All carers and from 0.00 to 8.16 for XI carers. The maximum values for both categories were recorded in Mallardstown, an ED in rural Kilkenny.

Figure 1 identifies a broad pattern where location quotients in 2002 for All and XI were categorised into three classes which identified low levels of relative caring $(<0.66)$, areas around the mean (0.66-1.33) and areas with high ( $>1.33)$ LQ scores. The rationale for this subdivision was to identify category breaks at approximately the same level of variation (approximating to one standard deviation) above and below the mean. In the case of the first category, the locations with the highest relative concentrations of general (All) caring seemed to be in a band running down the centre of the country, as well as along the western seaboard. Significantly, very few EDs in the highest LQ category $(>1.33)$ were found in any the eight city authorities and none at all in Inner City Dublin. For XI caring, the same categories were applied and a similar pattern appeared; although there were far more EDs falling into the highest category. For maximum-intensity caring, the lowest levels were found in the commuter areas, particularly around Dublin and Cork. In the case of XI caring, there were more EDs with high LQs found in cities, especially in what might be classified as older city districts such as Cabra in Dublin and Ballyphehane in Cork. This suggests that established urban communities are more likely to be involved in caring than newer, younger suburbs that have younger, healthier populations. One pattern noted was the tendency for EDs with higher LQ scores to be at the margins of individual counties and distant from the dominant county towns, which were generally located at the centre of
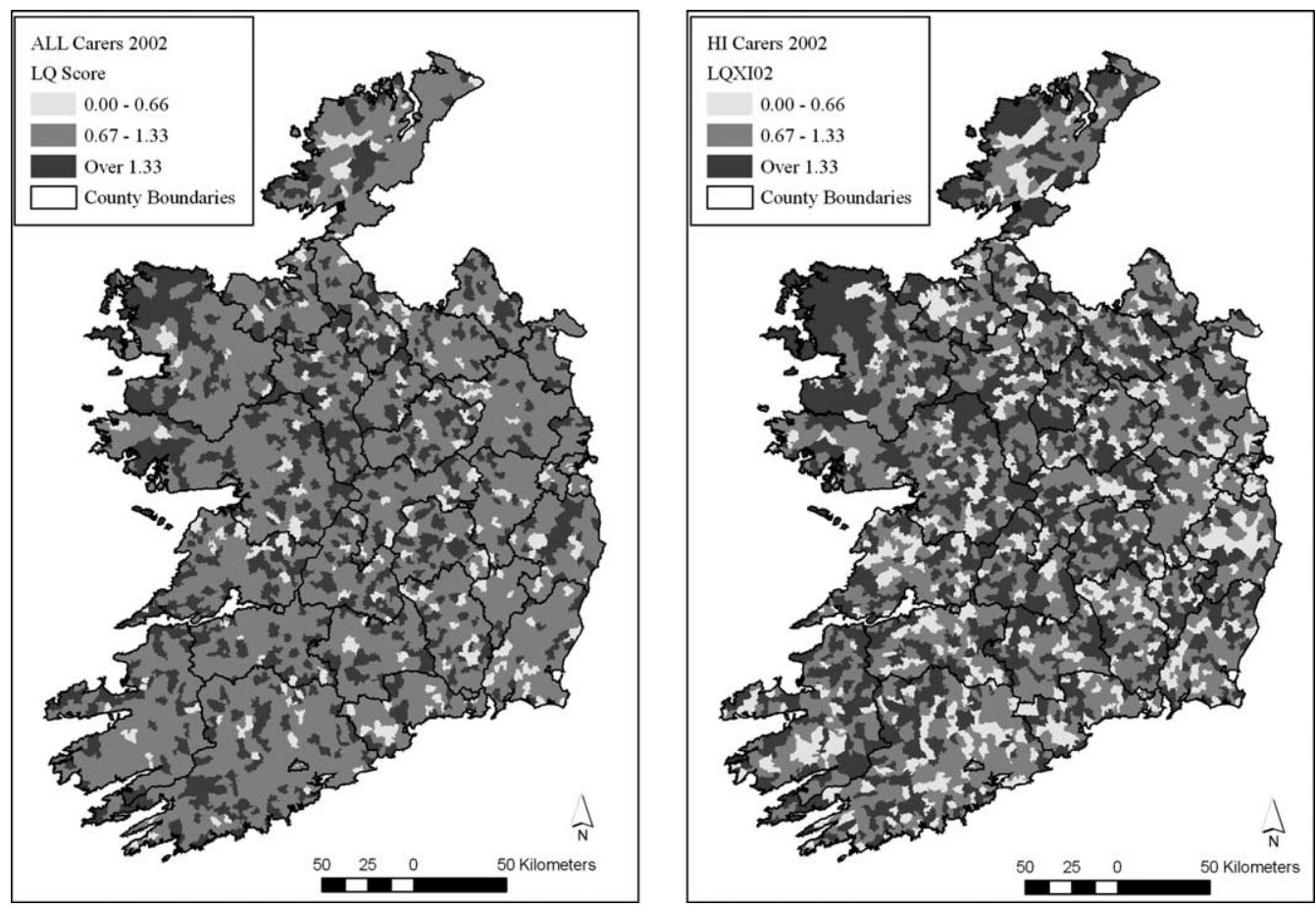

Figure 1. Spatial distribution of location quotients for All (ALL) and maximum-intensity (XI) carers, electoral division level, 2002. 

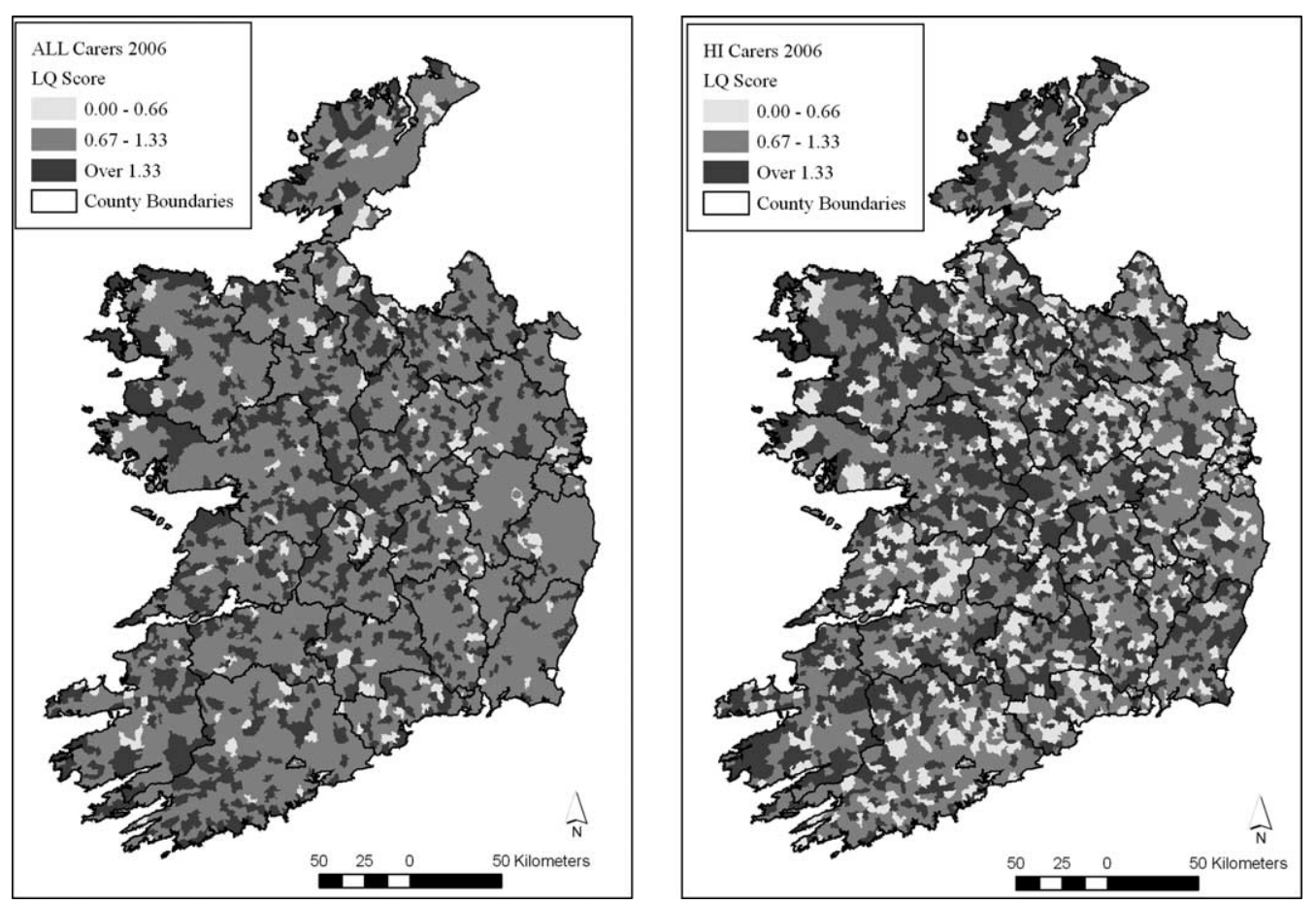

Figure 2. Spatial distribution of location quotients for All (ALL) and maximum-intensity (XI) carers, electoral division level, 2006.

counties. This marginalisation, even within rural counties, was also symptomatic of a caring burden being heaviest in remoter rural areas. This confirms the patterns observed at the broader spatial scales. Some care must be taken due to the problem of small numbers in some of the rural areas (especially in relation to the calculation of location quotients) and the heterogeneity of ED population size. Also significant was the absence of any high LQ scores in any of the urban areas for all carers. There were pockets of high levels of informal caring in most counties and the 'noise' associated with the small area effect made it difficult to pick out specific patterns, beyond the broad one noted above. The results, however, have some potential in supporting finer-level local needs assessment, something that has rarely been carried out at this scale in the past due to the lack of detailed data. Figure 2 identifies the same broad patterns for 2006 and there is little variation in these patterns when compared to Figure 1. The average LQ score at ED level for XI carers was unchanged at 1.17 between 2002 and 2006 .

\section{Discussion}

While it is of value to know base distributions, service planners and voluntary organisations also need to try to understand why these patterns exist and what relationships can be uncovered to explain them in terms of other census variables (The Equality Authority 2005). This has the dual benefit of establishing which variables have the strongest associations with caring and which could be utilised to help predict and model carer service provision into the future at a variety of geographical scales. Clearly, this relationship is never static as the relationships between caring and other data change over 
time. However, a snapshot in time still helps to uncover and identify relationships which can, in turn, be examined at future dates for stability and consistency. This area-based approach has been used in establishing statistical associations in other areas of health geography (Young et al. 2005). This initial exploration involved testing a number of variables which, while by no means comprehensive or statistically complete, were intended as an initial exploration to promote further qualitative work. The analysis was carried out primarily on the 2002 data as a number of the data sets, specifically those associated with deprivation, were not available for 2006.

While there are a number of different categories which could have potentially provided explanation, variables relating to the following categories were chosen as the most representative:

- Levels of disability [six categories; $\%$ disabled overall plus four age categories, $\%$ sick or disabled (a separate disability category based on inability to work)];

- Age-related family structure (two categories; retired, working in the home);

- Age group (four categories; 15-24, 25-44, 45-65, 65+);

- Gender (two categories, male and female). Only one gender is included as the numerical result for males tends to be 1 minus the proportion of females and is therefore statistically redundant;

- Deprivation (two categories; Haase-Pratschke Index and SAHRU Index); and

- Social class (two categories:\% in social classes 1 and 2,\% in social classes 5 and 6).

These categories were chosen in part because of the availability of measurements relating to them at small area scale from the 2002 Census or, in the case of deprivation, as derived from raw census data. More particularly, the categories were also identified from published literature on caring in Ireland, the UK and Europe as being those with the strongest associations with caring (Glendinning 2002; Doran et al. 2003; Power 2005). The relationship between caring and disability appeared an obvious one. Age-related family structure was important from a service perspective in helping to identify the available support levels and how these might be represented across different categories of carers (Lane et al. 2000; Garavan et al. 2001; Timonen 2002). While a number of categories around household formation, especially that of older households, were considered, these were not individual-level data and were therefore excluded. Reference has already been made to the role of age and gender in the provision of informal caring, with a particular burden being placed on female and middle-aged carers. Another factor noted in the regional and local results was the higher proportion of carers in rural areas. This was modelled initially against a coded set of different typologies of rural areas that was available (nine in total); however, due to its categorical nature and the exclusion of 'urban' EDs it could not be modelled directly with the other census data and as a result was excluded from the analysis (McHugh 2001). The relationship between deprivation and health care need is well understood, but to date little work has been conducted on examining the relationship between deprivation and social care need (McLaren and Bain 1998; Cubey 1999). The existence of national deprivation scores, such as the HaasePratschke Index of Deprivation (Haase and Pratschke 2005) and the Small Area Health Research Unit (SAHRU) Index (Kelly and Teljeur 2004), provided an option to test this relationship. In the subsequent statistical analysis the individual scores are used instead of deciles, but the core assumption is that caring is likely to be a greater burden on more deprived communities, whereas in more affluent areas, informal caring is less likely to be evident. In addition, two measurements of social class in the 2002 Census were used, 
specifically social classes 1 and 2 (used as a proxy measure of affluence) and social classes 5 and 6 (associated by proxy with deprivation). These latter variables were particularly important if income was to be suggested as a possible factor in service accessibility and utilisation. Evidence from England and Wales also suggested that there was an inverse relationship between high social class and high levels of caring (Young et al. 2005).

Table 2 uses a correlation approach to investigate two dependent variables, the proportion of all carers and the proportion of maximum-intensity caring. These two dependent variables were correlated against variables derived from the categories listed above. The two variables were chosen primarily to see if different values were uncovered which would help establish whether the associations were different for more intense levels of care. From a spatial data perspective, there were a number of problems associated with the raw data gathered at ED level. Many of the more rural EDs in Ireland have very small numbers, and this may be a confounding factor. An associated and perhaps more important issue was the great variation in ED populations. ED populations ranged from approximately 55 to more than 25,000 in 2002 , and this heterogeneity was potentially problematic for statistical analysis.

Table 2. Correlations for All (ALL) and maximum-intensity (XI) carers against selected variables, county and electoral division level in 2002.

\begin{tabular}{|c|c|c|c|c|c|}
\hline \multicolumn{2}{|l|}{ Dependent Variable: } & \multirow{2}{*}{$\begin{array}{c}\% \text { All Carers } \\
\text { County Scale } \\
\text { R Values }\end{array}$} & \multirow{2}{*}{$\begin{array}{c}\% \text { All Carers } \\
\begin{array}{c}\text { ED Scale R } \\
\text { values }\end{array}\end{array}$} & \multirow{2}{*}{$\begin{array}{c}\% \text { HI Carers } \\
\text { County Scale } \\
\text { R Values }\end{array}$} & \multirow{2}{*}{$\begin{array}{c}\% \text { HI Carers } \\
\begin{array}{c}\text { ED Scale R } \\
\text { values }\end{array}\end{array}$} \\
\hline Full Description & Code & & & & \\
\hline$\%$ Disabled & PRDISAB & $.471 * *$ & $.056^{* *}$ & $.638 * *$ & $.237 * *$ \\
\hline$\%$ Disabled 15-24 & PRD1524 & -.202 & $-.112 * *$ & -.131 & 0.008 \\
\hline$\%$ Disabled 25-44 & PRD2544 & -.111 & $-.134 * *$ & 0.039 & 0.017 \\
\hline$\%$ Disabled 45-64 & PRD4564 & 0.193 & $-.038^{*}$ & $.383^{*}$ & $.175 * *$ \\
\hline$\%$ Disabled over 65 & PRDIS65 & $.640 * *$ & $.134 * *$ & $.732 * *$ & $.213^{* *}$ \\
\hline $\begin{array}{l}\% \text { Sick or } \\
\text { Disabled }\end{array}$ & PRSIKDIS & $.347 * *$ & -0.002 & $.583 * *$ & $.241 * *$ \\
\hline$\%$ Retired & PRETIRE & $.611^{* *}$ & $.169 * *$ & $.697 * *$ & $.198 * *$ \\
\hline $\begin{array}{l}\% \text { Working in the } \\
\text { Home }\end{array}$ & PRHOMEWK & $.562 * *$ & $.257 * *$ & $.661 * *$ & $.344^{* *}$ \\
\hline$\%$ Aged 15-24 & PR15TO24 & $-.623 * *$ & $-.270 * *$ & $-.589 * *$ & $-.244 * *$ \\
\hline$\%$ Aged 25-44 & PR25TO44 & $-.777 * *$ & $-.321 * *$ & $-.783 * *$ & $-.323 * *$ \\
\hline$\%$ Aged 45-64 & PR45TO64 & $.762 * *$ & $.277 * *$ & $.596 * *$ & $.196 * *$ \\
\hline$\%$ Aged over 65 & PROVER65 & $.745^{* *}$ & $.199 * *$ & $.781 * *$ & $.233 * *$ \\
\hline$\%$ Female & PRFEM & $-.485 * *$ & $.032 * *$ & $-.489 * *$ & $-.136^{* *}$ \\
\hline $\begin{array}{l}\text { Haase-Pratschke } \\
\text { Index }\end{array}$ & HPDI02 & -.148 & 0.009 & $-.475^{* *}$ & $-.332 * *$ \\
\hline SAHRU Index & KDI02 & -.254 & $-.210^{* *}$ & 0.045 & $.136^{* *}$ \\
\hline $\begin{array}{l}\% \text { in Social Class } 1 \\
\text { and } 2\end{array}$ & PRSC12 & -.123 & $.079 * *$ & $-.474^{* *}$ & $-.273^{* *}$ \\
\hline $\begin{array}{l}\% \text { in Social Class } 5 \\
\text { and } 6\end{array}$ & PRSC56 & 0.191 & 0.019 & $.560 * *$ & $.310^{* *}$ \\
\hline
\end{tabular}

* Significant at 0.05 level

** Significant at 0.01 level

Source: CSO, 2007 
The large sample size was also an issue $(n=3424)$, as large samples often reveal higher levels of significance because of the higher $n$ values. Despite the statistical issues that arose with the nature of the raw data, preliminary data exploration in the form of scatter-plots suggested that they were both linear and normal. The difficulties with the heterogeneity of ED level data, in particular the small number problem, were countered by transforming the data using an empirical Bayes shrinkage technique, as suggested by Longford and others (Bailey and Gatrell 1995; Longford 1999). Taking a method of moments approach in applying an empirical Bayes shrinkage to the calculated proportions brought them closer to the mean (Bailey and Gatrell 1995). The basic formula used in the shrinkage was as follows:

$$
\hat{\theta}=\hat{\gamma}+\frac{\hat{\phi}(r-\hat{\gamma})}{\left(\hat{\phi}+\hat{\gamma} / n_{i}\right)}
$$

where $\hat{\theta}$ in the formula is the weighted sample variance of observed rates, $\hat{\gamma}$ is the pooled mean of observed rates and the shrinkage-weighting factor $w_{i}$ is expressed as:

$$
\frac{\hat{\phi}}{\left(\hat{\phi}+\hat{\gamma} / n_{i}\right)} .
$$

This shrinkage was applied at both county and ED level. While it was possible to apply a pooled mean calculation for each individual county, a quick check on the effect on the rates suggested that a national pooled mean was no less effective in the shrinkage process and this was used for the final calculation. As can be seen in Table 2, Table 17 individual variables from the six categories listed above were tested using a Pearson correlation and were tested simultaneously for significance. In Table 2 they are listed by County and ED level and by variable for the dependent variable, All and XI carers. At ED level, the results are expressed in terms of $r$ (and by extension $r^{2}$ ) values and significance to 0.05 and 0.01 levels. For All carers at ED level the highest association, at 0.257 , was for people working in the home followed by the proportion of residents aged over 65 at 0.199 . Both these results were significant at the 0.01 level. While no high positive $r$-values were evident at ED level, the majority were identified as significant, with many being significant at 0.01 levels. When the correlations for XI caring as a dependent variable were examined, some of the same variables emerged as having medium effects; namely, working in the home $(0.344)$ and the proportion of residents aged over $65(0.233)$. Again, both were significant at 0.01 level. Where maximum-intensity caring differed from the more generic caring figures, it was in a number of categories identified from the literature. In particular, a relatively high association at 0.310 was identified for the lower social classes 5 and 6 . Linked to this, the correlation for the Haase-Pratshcke Deprivation Index, with an $r$-value of -0.332 , is also important. While the value suggested an inverse relationship, the actual Haase-Pratschke values represented higher levels of deprivation with larger negative values; therefore it suggested a positive and significant relationship between high intensity caring and deprivation. At the other extreme, especially for the XI carers, negative associations were observed for a number of variables, such as younger age groups (15-24 and 25-44 years) and social classes 1 and 2 . This reflects findings from the literature suggesting that younger ages and affluence are associated with low levels of informal care. The figures for these variables were also significant. These latter groups were highly likely to be: (a) not 
involved in or in need of care and (b) involved in more formal caring by being looked after by statutory and voluntary agencies.

The data were also examined at county/local authority scale for the same dependent variables, All and XI caring. At this scale, there was a smaller sample $(n=34)$ and less of a numerical range within the data units used. The results in Table 2 for County level reflect some expected statistical findings given the smaller sample size; namely, higher $r$-values and less variables being identified as significant. Reflecting the ED level results, the relative proportion of residents in social classes 5 and 6 and the Haase-Pratschke Index, both variables linked to relative deprivation, had significant associations at county level with high intensity caring, with $r$ values of 0.560 and -0.475 , respectively (Cubey 1999; Young et al. 2005). Other particularly strong positive associations were identified with variables associated with age and disability; $r$-values of 0.781 for residents aged over 65 and 0.732 for older disabled populations emphasised this point, with both being significant at the 0.01 level. Additional related categories that also recorded significant correlations (at the 0.01 level) included $\%$ disabled, $\%$ retired and $\%$ sick or disabled. In addition, there were strong associations between XI caring and working in the home. There were strong negative associations between XI caring and social classes 1 and 2 and with the 15-24 and 25-44 age groups, which confirmed the ED level results and confirmed expected results based on wider research (Milligan 2000). One value which shows up as negative in the county level data is that of the percentage of females. The statistic suggests that there is a negative explanatory association at both county $(-0.489)$ and ED $(-0.485)$ level, between being a XI carer and being female. This runs counter to the literature, but given the generic category of female it may suggest that intensities of caring, especially by age, may be hidden in that figure. Unfortunately, caring by age breakdowns were not available at ED level to test this out fully.

Although the initial analysis identified a number of valuable associations through correlation, a brief examination of causality was also explored using multiple regression (via a stepwise method with a cut-off significance level of $P<0.005$ for model cut-off) to see if it was possible to predict an outcome (levels of maximum intensity caring) from a smaller number of predictor variables, specifically those related to age, social class and deprivation. The results are listed below:

$$
\begin{gathered}
\text { ED level: } Y=0.05+0.33 X_{1}+0.26 X_{2}-0.08 X_{3} \mathrm{r}^{2}=0.204 \\
\text { County level: } \mathrm{Y}=-0.06+0.077 X_{1}+0.094 X_{2} r^{2}=0.78
\end{gathered}
$$

where: $Y=$ percentage of HI carers; $X_{1}=$ percentage working in the home; $X_{2}=$ percentage disabled and $X_{3}=$ percentage in social classes five and six; $P<0.000$.

At ED level, model 1 suggested from the $r^{2}$ value that the main predictor, the percentage of people working in the home, accounted for about $11.8 \%$ of the variation in maximum-intensity caring. Within model 2 , the two variables, working in the home and percentage disabled together, predicted $18.5 \%$ of XI caring. Model 3, which added the variable recording the proportion of residents in social classes 5 and 6 , added only a very small amount to the model, bringing the total proportion of variation in the outcome to $20.4 \%$. At county level the same variables emerged, although there were only two models rather than three. The $r^{2}$ values were much higher, with working in the home accounting for $43.7 \%$ of the variation in maximum-intensity caring at county level. With the addition of the disability variable, the two together accounted for over $78 \%$ of the variation in XI caring at a county level. The fourth variable tested, the Haase-Pratschke Deprivation Index, dropped out of the model and was less important than the other variables in explaining variations in XI caring. Clearly a number of caveats arise in relation to the 
number of observations when compared to the ED level and possible other important explanatory categories that have not been included in the model. Additionally, identifying the direction of causality can be a complex process. It may well be that in many cases, the reasons that people are working in the home is precisely because they are carers. None the less, these results suggest that being a homemaker and having a friend or relative with a disability is, unsurprisingly, likely to significantly affect one's chances of being a carer. The key point to emerge was that at both spatial scales of analysis the same two variables emerged as being the most important. Overall, the examination of statistical associations revealed some significant results and suggested an overall pattern whereby higher levels of caring were associated with relative poverty/deprivation, an economically driven relationship which has also been observed in the UK (Rowlands 1998).

\section{Conclusion}

This paper has emphasised that the spatial distribution of carers within Ireland was and is a complex arena, with additional variations associated with the intensity of the amount of care provided. Nationally, rates of caring in all categories were higher in rural than in urban areas. Some clear spatial patterns existed in the country as measured in both 2002 and 2006, with rural regions such as the West and Midlands showing up as caring 'hotspots'. The absence of high levels of general caring from the cities also emphasised this rural-urban split. There was a stability to these patterns, both temporally and spatially, that was also of significance for forecasting and planning. The nature and intensity of caring was also influenced by the spatial scale of examination. This was shown in the statistical data presented in Table 1 and Figure 1Fig. 2, at both regional (Local Authority) and local (ED) scales. Greater intensities of caring, as measured through the location quotients, were observable at ED level. One important finding was that those greater intensities had a spatial manifestation in two distinct types of area: established inner-city districts and around the margins of rural counties. As an aid to understanding the observed spatial patterns, the relationships with a number of important associated variables were analysed additionally. This modelling, although relatively basic in statistical terms, identified some positive and significant relationships, with a number of variables identified as potentially explanatory from the literature, specifically, old age, disability, social class and deprivation. In addition, regression analysis suggested that working in the home and disability were significant predictors for maximum-intensity caring. Although difficult to establish clearly from the statistical analysis, the ongoing equity of the caring burden continues to fall on home-makers who are, more often than not, likely to be women, who in turn are likely to be looking after disabled family members or friends.

While there is a 'geography' of caring as such, it is important that these broad empirical patterns are translated sensibly into planning discussions on service demand and needs assessment. Some aspects of this demand and the likelihood of the need for informal care are clearly spatially determined, and although hard to predict suggest some contextual influences at work. There are a number of additional explanatory factors, not examined here, that affect individuals and essentially force partners and other family members to become carers. Although not directly spatial, factors such as genetic susceptibility, life events and personal choice still have a spatial expression related to individual places through individual compositional effects (Gatrell 2002). Information about these factors is more difficult to collect and access, but qualitative analysis at more local levels may be effective in providing additional explanation (Foley 2002; Milligan 2001). Additionally, the work of Duncan and Smith (2002) on spatial variations in family formations may point 
towards further explanation in this area, linked as they are to the impacts of social class and deprivation, where traditional working-class families are more likely to be both deprived and providing care. From the viewpoint of age, patterns of movement associated with retirement may also need to be considered when identifying geographies of carers, although this may arguably be less severe an issue in Ireland than in the UK, where larger volumes and the explicit clustering of retirement communities in specific counties is more visible (Milligan 2001; Doran et al. 2003). Despite the increasing wealth of information sources and the ability to cross-tabulate information on caring and disability, key issues relating to the specific and precise nature of caring will always be difficult to forecast and will require local surveys and individual service usage data (Stalker 1994; Dixie and Dorling 2002).

Although still in development, there are a number of other explanations of the changing nature of caring. These relate in part to significant changes in family form within society as a whole, with larger numbers of single-person households in all age categories, higher levels of divorce and single-parenthood and the more dispersed nature of family relationships within an increasingly mobile society. In a sense, this lack of fixity in families and places may also reflect wider societal changes in social capital and the beginnings of a shift in older forms of familial and community care (Milligan and Conradson 2006). The results, which showed that maximum-intensity caring in cities is associated with wellestablished city neighbourhoods, support this contention. In an Ireland where traditional family structures have altered radically in the past few decades, these traditional family supports are being lost against the backdrop of the economic boom of the 'Celtic Tiger'. The ability to 'buy in' care may also be a significant factor, as the traditional voluntary sector is either pressed into running its services along more economic lines or, in areas where in the absence of services, the private sector is beginning to fill a gap, especially around elderly care (O’Shea 2000; The Equality Authority 2005).

This work provides an initial empirical basis for the better understanding of carer distributions in Ireland. The patterning, and more specifically intensities of caring activities noted in the paper, may also have the potential to act as proxies for expressed and potential need across the country as well. It should also be noted that when using carer distributions as spatial proxies of need there is considerable complexity in carer/care recipient relationships, which are more difficult to uncover. Given that some of the correlations between carers and those potentially needing care are relatively poor, it suggests that carers provide informal support to a very wider range of care recipients. One of the main rationales for this work was to start the process of providing an evidence base for applied service planning. A logical next step would be to map the location of services for carers to explore patterns of spatial inequity through GIS-based overlays. The identification of gaps in provision and even utilisation is likely to be a particularly difficult area in which to access information, given the fact that much of the service support and short-term care is provided by voluntary agencies and the data are sensitive and confidential.

Formally, there is already an acknowledgment of a lack of spatial equity and lack of provision within Ireland when service provision is nominally mapped against service need (Houses of the Oireachtas Joint Committee 2003; The Equality Authority 2005). It is also clear that the lack of a statutory basis for service provision and the ad hoc nature of service locations almost by definition give rise to spatial inequities and plentiful examples of inverse care, where there is a mismatch between health service supply and need (The Equality Authority 2005). Whether the state responds to this inequity or passes the responsibility to the voluntary agencies will need to be tracked carefully over the next 
decade or so. The existence of a full and detailed data set on informal caring in Ireland is an important first step in this process. Hopefully, other geographers might develop this work to tease out these issues and explore further the spatial dimensions of carer research.

\section{References}

Ashworth, M. and Baker, A., 2000. Time and space: carers' views about respite care. Health and Social Care in the Community, 8 (1), 50-56.

Bailey, T. and Gatrell, A., 1995. Interactive spatial data analysis. Harlow: Longman.

Boyle, P., Gatrell, A.C., and Duke-Williams, O., 2001. Do area-level population change, deprivation and variations in deprivation affect individual-level self-reported limiting long-term illness? Social Science \& Medicine, 53 (6), 795-799.

Carers UK, 2005. Consultation on 2011 census topics. Available from: http://www.carersuk.org/ Policyandpractice/Responsestogovernment/Censustopics.pdf [Accessed 28 October 2006].

Central Statistics Office, 2004. Census of Ireland 2002, volume 10. Disability and carers. Dublin: Stationery Office.

Central Statistics Office, 2005. Census 2002 website. Available from: http://www.cso.ie/census/step_2025.htm [Accessed 28 October 2006].

Central Statistics Office, 2007. Census of Ireland 2006, volume 11. Disability, carers and voluntary activities. Dublin: Stationery Office.

Cubey, D., 1999. Deprivation indexes: do they measure up? Research Policy and Planning, 17 (2). Available from: http://www.ssrg.org.uk/publications/rpp/1999/issue2/article4.asp [Accessed 12 January 2006].

Curtis, S., 2004. Health \& inequalities: geographical perspectives. London: Sage.

Dixie, J. and Dorling, D., 2002. New questions for the 2001 Census; part VI. Planning for 2001 census outputs. In: P.H. Rees, D. Martin and P. Williamson, eds. The census data system. Chichester: John Wiley, 283-293.

Doran, T., Drever, F., and Whitehead, M., 2003. Health of young and elderly informal carers: analysis of UK census data. British Medical Journal, 327, 1388.

Duncan, S. and Smith, D., 2002. Geographies of family formations: spatial differences and gender cultures in Britain. Transactions of the Institute of British Geographers, 27 (4), 471-493.

Foley, R., 2002. Assessing the applicability of GIS in a health and social care setting: planning services for informal carers in East Sussex, England. Social Science \& Medicine, 55 (1), 79-96.

Fyfe, N. and Milligan, C., 2003. Space, citizenship and the 'shadow state'; exploring the voluntary welfare sector in Glasgow. Environment and Planning C: Government and Policy, 35, 397-413.

Garavan, R., Winder, R., and McGee, H., 2001. Health and social services for older people (HeSSOP). Report no. 60. Dublin: National Council on Ageing and Older People.

Gatrell, A., 2002. Geographies of health. London: Blackwell.

Glendinning, C., 2002. European policies on home care services compared. In: B. Bytheway, V. Bacigalupo, J. Bornat, J. Johnson, and S. Spurr, eds. Understanding care, welfare and community. London: Routledge, 299-312.

Glendinning, C. and McLaughlin, E., 1993. Paying for care: lessons from Europe. Social Security Advisory Committee Research Report 5. London: HMSO.

Guidera, A., 2001. Home carers 'save State £2bn a year'. Irish Independent, 16 July 2001, Dublin.

Haase, T. and Pratchske, J., 2005. Deprivation and its spatial articulation in the Republic of Ireland: new measures of deprivation based on the Census of Population, 1991, 1996 and 2002. Dublin: ADM.

Hanlon, N.T., 2001. Sense of place, organizational context and the strategic management of publicly funded hospitals. Health Policy, 58 (2), 151-173.

Houses of the Oireachtas Joint Committee on Social and Family Affairs, 2003. First Report on the Position of Full-time Carers. PN 1378. Dublin: Stationery Office.

Joseph, A.E. and Phillips, D.R., 1984. Accessibility and utilization: geographical perspectives on health care delivery. New York: Harper \& Row.

Kalogirou, S. and Foley, R., 2007. Spatial trends of unpaid caregiving in Ireland. Proceedings of the GIS Research UK Conference 2007, NUI Maynooth, 11-13 April, 435-440.

Kearns, R., 1993. Place and health: towards a reformed medical geography. Place and Health, 45 (2), 139-147. 
Kelly, A. and Teljeur, C., 2004. A new national deprivation index for health and health services research. Dublin: SAHRU.

Lane, P., McKenna, H.P., Ryan, A., and Fleming, P., 2000. Listening to the voice of carers: an exploration of the health and social care needs and experiences of informal carers of older people. Waterford: South Eastern Health Board.

Longford, N.T., 1999. Multivariate shrinkage estimation of small area means and proportions. Journal of the Royal Statistical Association A, 162, 2, 227-245.

McHugh, C., 2001. A spatial analysis of socio-economic adjustments in rural Ireland 1986-1996. Unpublished PhD thesis, Maynooth, National University of Ireland, Maynooth.

McLaren, G.L. and Bain, M.R.S., 1998. Deprivation and health in Scotland: insights from NHS data. Edinburgh: ISD Scotland Publications.

Milligan, C., 1998. Pathways of dependence: the impact of health and social care restructuring - the voluntary experience. Social Science \& Medicine, 46 (6), 743-753.

Milligan, C., 2000. 'Bearing the burden': towards a restructured geography of caring. Area, 32 (1), 49-58.

Milligan, C., 2001. Geographies of care: space, place and the voluntary sector. Aldershot: Ashgate.

Milligan, C. and Conradson, D., eds., 2006. Landscapes of voluntarism: new spaces of health, welfare and governance. Bristol: Policy Press.

Office of National Statistics, 2003. Census 2001 census forms (online). London: Office of National Statistics. Available from: http://www.statistics.gov.uk/census2001/censusform.asp [Accessed 14 April 2003].

O'Neill, S. and Evans, D., 1999. Informal care in the Western Health Board: a study of carers, people receiving care and non-carers. Galway: The Department of Public Health, Western Health Board.

O'Shea, E., 2000. The costs of caring for people with dementia and related cognitive impairments. Report no. 60. Dublin: National Council on Ageing and Older People.

Parker, G., 1992. Counting care: numbers and types of informal care. In: R. Twigg, ed. Carers. Research and practice. London: HMSO, 6-29.

Parker, G. and Lawton, D., 1994. Different types of care, different types of carer: evidence from the General Household Survey. London: HMSO.

Power, A., 2005. Landscapes of care: a geographical study of informal care and care support in ireland using international comparisons. Unpublished $\mathrm{PhD}$ thesis, Maynooth, National University of Ireland, Maynooth.

Rowlands, O., 1998. Informal carers. Results from an independent study carried out on behalf of the Department of Health as part of the 1995 General Household Survey. London: HMSO.

Shaw, M., Dorling, D., and Mitchell, R., 2002. Health, place, and society. New York: Prentice Hall.

Skinner, M.W. and Rosenberg, M., 2005. Co-opting voluntarism? Exploring the implications of longterm care reform for the non-profit sector in Ontario. Environment and Planning C: Government and Policy, 23, 101-121.

Stalker, K., 1994. The best laid plans ... gang aft agley?' Assessing population needs in Scotland. Health and Social Care in the Community, 2 (1), 1-9.

Stalker, K., 1996. Developments in short-term care: breaks and opportunities. London: Jessica Kingsley.

The Equality Authority, 2005. Implementing equality for carers. Dublin: The Equality Authority.

Thomas, C. and Morris, S.M., 2002. Informal carers in cancer contexts. European Journal of Cancer Care, 11 (3), 178-182.

Timonen, V., 2002. Supporting carers - a social policy report. Dublin: Comhairle.

Wiles, J., 2003. Daily geographies of caregivers: mobility, routine, scale. Social Science and Medicine, 57 (7), 1307-1325.

Williams, A., 1996. The development of home care in Ontario: a critical geographical analysis. Social Science \& Medicine, 42 (6), 937-948.

Williams, A., 2002. Changing geographies of care: employing the concept of therapeutic landscapes as a framework in examining home space. Social Science \& Medicine, 55 (1), 141-154.

Young, H., Grundy, E., and Kalogirou, S., 2005. Who cares? Geographical variation in informal caregiving in England and Wales: evidence from the 2001 Census. Population Trends, 120, 23-34. 